\title{
A Level of Care Instrument for Children's Systems of Care: Construction, Reliability and Validity
}

\author{
Theodore Fallon, Jr., M.D., M.P.H., ${ }^{1,12}$ Andres Pumariega, M.D., ${ }^{2}$ \\ Wesley Sowers, M.D., ${ }^{3}$ Robert Klaehn, M.D., ${ }^{4}$ Charles Huffine, M.D., ${ }^{5}$ \\ Thomas Vaughan, Jr., M.D., ${ }^{6}$ Nancy Winters, M.D., ${ }^{7}$ Mark Chenven, M.D., ${ }^{8}$ \\ Larry Marx, M.D., ${ }^{7}$ Albert Zachik, M.D., ${ }^{9}$ William Heffron, M.D., ${ }^{10}$ \\ and Katherine Grimes, M.D., M.P.H. ${ }^{11}$
}

Published online: 9 February 2006

The Child and Adolescent Level of Care System/Child and Adolescent Service Intensity Instrument (CALOCUS/ CASII) is designed to help determine the intensity of services needed for a child served in a mental health system of care. The instrument contains eight dimensions that are rated following a comprehensive clinical evaluation. The dimensions are risk of harm, functionality, co-morbidity (psychiatric, substance abuse, development disability and medical), environmental stressors, environmental supports, the child's resiliency, and the child and family's willingness to engage in treatment. An algorithm connects the ratings to a level of care recommendation. The instrument specifies six levels of care defined flexibly enough to consider whatever services are available. The results of psychometric testing using raters with a broad range of clinical experience and training from four different systems of care around the country are presented. The testing demonstrates excellent reliability when rating vignettes. Using children and adolescents

\footnotetext{
${ }^{1}$ Faculty, Psychoanalytic Center of Philadelphia, Philadelphia, PA.

${ }^{2}$ Professor and Director, Child and Adolescent Psychiatry, East Tennessee State University, Johnson City, TN.

${ }^{3}$ Medical Director, Allegheny County Office of Behavioral Health, Pittsburgh, PA.

${ }^{4}$ Medical Director, Maricopa Integrated Health System, Phoenix, AZ.

${ }^{5}$ Professor, Department of Psychiatry, University of Washington, Seattle, WA.

${ }^{6}$ Vice President for Behavioral Health, Children's Hospital of Birmingham, Birmingham, AL.

${ }^{7}$ Associate Professor, Psychiatry, Oregon Health Sciences University, Portland, OR.

${ }^{8}$ Senior Vice President for Clinical Operations, Vista Hill Foundation, San Diego, CA.

${ }^{9}$ Director of Child and Adolescent Services, Maryland Department of Mental Health, Baltimore, MD.

${ }^{10}$ Associate Professor, Department of Psychiatry, University of Kentucky, Louisville, KY.

${ }^{11}$ Assistant Professor, Department of Psychiatry, Harvard Medical School, Boston, MA.

${ }^{12}$ Correspondence should be directed to Theodore Fallon, P.O. Box 81, Chester Springs, PA 19425; e-mail: Corinne7@Verizon.net.
} 
in live system of care clinical settings, the CALOCUS/CASII demonstrates reasonable validity when compared with the Child Global Assessment Scale, and the Child and Adolescent Functional Assessment Scale.

KEY WORDS: The Child and Adolescent Level of Care System/Child and Adolescent Service Intensity Instrumen; intensity of services for children and adolescents; level of care.

In the context of rising health-care costs and an increasing demand for mental health services, there is a need for objective tools that will help to balance the equation between resource availability and individual clinical need. Solving this equation would give our health system (and our society) the opportunity to use our mental health resources most responsibly and effectively (Fallon \& Dogin, 2005). For child and adolescent mental health, the challenge to balance this equation is even greater than in other areas of health and mental health because, in contrast to adults, children have multiple developmental needs. These are reflected in the child's dependence on his/her family and environment. In the context of serious emotional disturbance, these developmental needs require more resources, adding greater imperative for coordination of care.

In an effort to balance this equation, there have been many attempts to manage mental health care. From outside the field, legislative bodies, administrative entities, and even courts have attempted to monitor and allocate resources. From within, there have been a number of attempts to devise schemes for determining service need. Initial attempts were related to identifying diagnostic entities and symptom groupings. In medicine, for example, the Diagnostic Related Groups were introduced in the early 1980s (Haley, 1980). For adult mental health, the Diagnostic Interview Schedule (Endicott, 1981) was used as an instrument to determine the presence and burden of mental illness within the general population. For child mental health, instruments such as the Kiddie Schedule for Anxiety, Depression and Schizophrenia (Ambrosini \& Dixon, 1996), the Diagnostic Interview Schedule for Children (Shaffer et al., 1993), and the Diagnostic Interview for Children and Adolescents (Welne, Reich, Herjanic, Jung, \& Amado, 1987) were introduced. Over the years, with considerable amount of experience and empirical evidence, these diagnostic entities and instruments have been further refined. This work has shown that although grouping of symptoms may be useful for clinical purposes, disorder classifications do not determine service need. This is true for both health care (Curtiss, 1985) as well as mental health care (Newman, Griffin, Black, \& Page, 1989).

In response to this realization, the assessment of function arose. Several scales were designed to assess child mental health function including the Child Global Assessment Scale (CGAS; Shaffer et al., 1983), and the Child and Adolescent Functional Assessment Scale (CAFAS; Hodges \& Wong, 1996). In recent years, these measures have been used widely to assign levels of care, especially within public mental health systems for children. Studies using the CAFAS demonstrated 
correlation between extent of child mental health services use and degree of functional impairment (Hodges, Doucette-Gates, \& Kim, 2000).

Even functional measures, however, fail to take into account the full contextual picture. In both clinical evaluation and in various studies, level of care placement and degree of mental health service use has been associated with a wide range of variables. In addition to demographic (age, gender, and race/ethnicity) and clinical factors (Alegria et al., 2004), other factors have included the child's psychosocial strengths, history of abuse/traumatization (Anderson \& Estle, 2001), degree of family disadvantage and stress (Hazell, Tarren-Sweeney, Vimpani, Keatinge, \& Callan, 2002), parental burden and caregiver strain (Brannan, Heflinger, \& Foster, 2003), community resource capacity, community cohesion (Van der Linden, Drukker, Gunther, Feron, \& Van Os, 2003), previous service use (Anderson \& Estle, 2001), and parental perception, concern, and acceptance of the child's problem (Teagle, 2002).

Some researchers, such as Foster, Saunders and Summefeldt (1996), have analyzed level of care data and associated factors and developed empirical algorithms that combine many of these factors in predicting different levels of care. The recognition of these factors, however, does not lead to reliable and accurate level of care placement decisions. For example, Bickman, Karver, and Schut (1997) developed 47 child and adolescent clinical profiles consisting of 48 variables. These were used for level of care determination by 18 clinicians trained in their agency's level of care guidelines. Their inter-rater reliability in assigning a child to an appropriate level of care was close to zero (kappa $=.07$ ).

Some of the first attempts to develop systematic tools and methods to assess these additional factors occurred in the managed care environment in the early 1990's. Both the Level of Care Assessment Tool (LOCAT) and the Green Spring Health Services' Medical Necessity Criteria for Utilization Management tool (Book, Harbin, Marques, \& Silverman, 1995) were proprietary and not available, even to the clinical practitioners caring for the patients. Other instruments, such as the Level of Need-Care Assessment (Uehara, Smukler, \& Newman, 1994), and American Society of Addiction Medicine criteria (ASAM; McKay, Cacciola, McLellan, Alterman, \& Wirtz, 1997), were available publically.

Given that many of these instruments were designed primarily for fiscal reasons, they did not have a clear clinical organization or orientation. They tended to be a checklist of items, sometimes quite long and complex, with the main goal of resource rationing. Organizing and conveying this information in an understandable manner was burdensome and challenging to clinicians who were reluctant to use such tools, even when the tools were available. Also, initial instruments such as ASAM and others (Deane, Huzziff, \& Beaumont, 1995) had only a few defined categorical levels of care. Over time, these categorical levels of care have changed meaning. For example psychiatric hospitalization in the 1980 s tended to be weeks and aimed at treatment, while recent trends focus on risk reduction and tend to be a few days. In addition, most instruments were designed for adults. 
The Child and Adolescent Severity of Psychiatric Illness (CASPI) (Lyons, Mintzer, \& Kisiel, 1998), one of the few instruments designed for children, was initially used in assessing the need for residential treatment, and later expanded to consider all levels of need. This instrument considers the dimensions of symptoms, risk behaviors and caregiver capacity. The recommended levels of care consider milieu intensity and service intensity. A more recent instrument, the Child and Adolescent Needs and Strength instrument (CANS), was patterned after the CASPI and has demonstrated concurrent reliability in field testing, and has been used to evaluate service use within public mental health and juvenile justice systems (Lyons, Griffith, Quintenz, Jenuwine, \& Sasha, 2003; Lyons et al., 2004). However, both of these instruments are dependent on diagnostic categorization, which is often difficult to achieve in children due to lack of diagnostic clarity as well as high rates of co-morbidities.

With the trend in the mental health field moving toward a comprehensive community-based continuum of services and interagency systems of care, an instrument that has utility across different agency and service settings would offer an advantage. In addition, there is a trend to tailor services to individual need rather than fitting cases to categorical services demanding instruments that are flexible and make finer distinctions in levels of care (Foster et al., 1996). In response, more recently designed instruments have had as many as 8 levels of care (Srebnik, Uehara, \& Smukler, 1998).

One example is the Level of Care Utilization System (LOCUS) for adults (Sowers, George, \& Thompson, 1999). This instrument defines six levels of care in addition to recommending the basic services that should be available to everyone in the community. The instrument requires a standard clinical evaluation, after which patients are rated on six dimensions: dangerousness, function, co-morbidity, environmental stresses and supports, treatment history and willingness to engage in treatment. Finally, an algorithm connects these ratings with a level of care recommendation. Although the promising data on the psychometric properties of the LOCUS is only preliminary (Sowers et al., 1999), the instrument has been used widely. One of the reasons for its wide acceptance appears to be its intuitive clinical appeal. The instrument asks clinicians to make judgments about the patient's life with which they become familiar through their evaluation. On the other side of the equation, it provides sufficient information necessary to determine a level of care in a simple, yet flexible manner. When deciding a level of care for children and adolescents, there are different and additional factors to consider, for example, the child's level of development in the context of the family and parents. Therefore, an instrument designed specifically for children and adolescents becomes critical, especially when considering the quantity of resources our society allocates to children.

In this paper, we discuss such an instrument known both as the Child and Adolescent Level of Care Utilization System (CALOCUS) and the Child and 
Adolescent Service Intensity Instrument (CASII). The CASII/CALOCUS is designed to consider the unique clinical and psychosocial needs of the child and the family. By rating the child, the family, and the child's environment, the CASII/CALOCUS leads to a level of care recommendation around which an individualized treatment plan can be developed. We also report on the initial evaluation of the reliability and validity of this instrument.

\section{DEVELOPMENT OF THE CASII/CALOCUS}

Members of the American Academy of Child and Adolescent Psychiatry's (AACAP) Work Group on Community Systems of Care collaborated with the American Association of Community Psychiatrists (AACP), developers of the LOCUS, to create the CASII/CALOCUS-a scale that assists in the determination of level of care for children and adolescents with developmental ages of 6 to 18 years. The CASII/CALOCUS was developed as a consensus among the 12 authors along with consultation from a broad diverse group of clinicians. It was designed to facilitate communication between personnel involved on both sides of the equation, clinical need as well as resource availability and management, and to create a standard context in which all participants work together.

The CASII/CALOCUS differed from the adult LOCUS, however, in its consideration of child development and the importance of the parents and the community in supporting the child. It took into consideration developmental disorders such as mental retardation, autism and delinquency, and considered the contributions of the child/adolescent as well at the parent, family and child's environment, including the school and community. Levels of care were clearly defined within interagency systems of care philosophy (Stroul \& Friedman, 1996), using wraparound concepts (VanDenBerg \& Grealish, 1996) in which services are child-centered, family driven, culturally competent (Pumariega \& Cross, 1997), and individualized to the child's multiple needs and context. The CASII differs from the CALOCUS in the AACAP's requirement that users be clinicians who are trained to consider the clinical judgments necessary for accurate CASII ratings. In contrast, the AACP refrains from specifying personnel qualifications or training. In this report, we followed the AACAP's recommendations on rater qualification and training and report on the results of the CASII.

\section{STRUCTURE OF THE CASII/CALOCUS}

The CASII/CALOCUS links a clinical assessment with standardized "levels of care." In preparation for the scoring, the CASII/CALOCUS requires a comprehensive clinical assessment of the child and his/her environment. Once this is completed, the child and his/her environment are scored on 8 dimensions. Table I 
Table I. CASII/CALOCUS Dimensions

\begin{tabular}{|c|c|}
\hline Risk of Harm & $\begin{array}{l}\text { This dimension is the measurement of a child or adolescent's risk } \\
\text { of harm to self or other as well as an assessment of his/her } \\
\text { potential for being a victim of physical or sexual abuse, or } \\
\text { neglect }\end{array}$ \\
\hline Functional Status & $\begin{array}{l}\text { This dimension measures the impact of a child or adolescent's } \\
\text { primary condition on his/her daily life. It is an assessment of } \\
\text { the child's ability to function in all age-appropriate roles: } \\
\text { family member, friend and student. It is also a measure of the } \\
\text { effect of the primary problem on such basic daily activities as } \\
\text { eating, sleeping and personal hygiene }\end{array}$ \\
\hline Comorbidity & $\begin{array}{l}\text { This dimension measures the co-existence and interaction of } \\
\text { disorders across four domains: Medical, Substance Abuse, } \\
\text { Development Disability or Delay and Psychiatric }\end{array}$ \\
\hline Recovery Environment & $\begin{array}{l}\text { This dimension is divided into } 2 \text { subscales: Environmental Stress } \\
\text { and Environmental Support. An understanding of the strengths } \\
\text { and weaknesses of the child or adolescent's family is essential } \\
\text { to choosing an accurate rating in this dimension. It is also a } \\
\text { measure of the neighborhood and community's role in either } \\
\text { stressing or supporting the child or adolescent }\end{array}$ \\
\hline $\begin{array}{l}\text { Resiliency and Treatment } \\
\text { History }\end{array}$ & $\begin{array}{l}\text { Resiliency refers to a child or adolescent's innate or constitutional } \\
\text { emotional strength, as well as the capacity for successful } \\
\text { adaptation. The concept of resiliency is familiar to clinicians } \\
\text { who treat children or adolescents who have the most severe } \\
\text { disorders and/or survive the most traumatic life circumstances, } \\
\text { yet who either maintain high functioning and developmental } \\
\text { progress, or use treatment for a rapid return to that state. This } \\
\text { dimension also measures the extent to which the child or } \\
\text { adolescent and his/her family has responded to past treatment }\end{array}$ \\
\hline $\begin{array}{l}\text { Acceptance and Engagement } \\
\text { (Scale A-Child/Adolescent; } \\
\text { Scale B-Parents/Primary } \\
\text { Caretaker) }\end{array}$ & $\begin{array}{l}\text { This dimension is divided into two subscales to allow for } \\
\text { measurement of both the child's or adolescent's and his/her } \\
\text { family's acceptance and engagement. Clearly the child or } \\
\text { adolescent's treatment benefits when the family is proactively } \\
\text { and positively engaged, and conversely, treatment suffers when } \\
\text { the family is disinterested, disruptive or openly hostile toward } \\
\text { the process. Only the highest subscale score (the subscale } \\
\text { indicating the most significant challenge to treatment) is used in } \\
\text { calculating the composite score. }\end{array}$ \\
\hline
\end{tabular}

Note. Each dimension has a five point rating scale. For each of the five possible ratings within each dimension, a set of criteria is clearly defined.

summarizes the definitions of each dimension. Although these dimension scores require clinical judgment, they are standardized using anchor points. The ratings are quantified in order to convey information easily, but also provide a spectrum along which a child/adolescent may lie. The dimensions are simple yet specific in their content. The CASII/CALOCUS rating can be done for any child in any setting regardless of diagnosis or service agency (child welfare, juvenile justice, mental health, medical or educational) with which the child is involved. To support this ability, the instrument considers four distinct types of potential co-morbid areas: psychiatric, substance use, developmental (including autism and mental retardation), and medical. 
Table II. CASII/CALOCUS Levels of Care

Level 0: Basic Services

Level 1: Recovery Maintenance and Health Management

Level 2: Outpatient Services

Level 3: Intensive Outpatient Services

Level 4: Intensive Integrated Service Without 24-Hour Medical Monitoring

Level 5: Non-Secure, 24-Hour, Medically Monitored Services

Level 6: Secure, 24-Hours, Medically Managed Services
This is a basic package of prevention and health maintenance services that are assumed to be available to all people in the community

This level of service is usually reserved for those stepping down from higher levels of care that need minimal system involvement to maintain their current level of function or need brief intervention to return to their previous level of functioning. Examples of this level of service are: children or adolescents who only need ongoing medication services for a chronic condition or brief crisis counseling

This level of care most closely resembles traditional once a week visits

This level of service can range from a couple visits per week up to a few hours for three days per week and may include multiple services (e.g., big brother, church services, mental health services) necessitating coordination (case management)

This level of care best describes the increased intensity of services necessary for the "multi-system, multi-problem" child or adolescent requiring more extensive collaboration between the increased number of providers and agencies. A more elaborate Wraparound plan is also required, using an increased number of formal supports. Additional supports may include respite, homemaking services or paid mentors. In more traditional systems, this level of service is often provided in a day treatment or partial hospitalization setting. Active case management is essential at this level of care

Traditionally, this level of care has provided a safe residence and has including group home, foster care or a residential facility, but can also be provided by a tightly knit array of Wraparound services in the community

Most commonly, these services are provided in inpatient psychiatric settings or highly programmed residential facilities. If security needs can be met through the wrap-around process, then this level of intensity of service could also be provided in a community setting. Case management remains essential to make sure that the time each child spends at this level of care is held to the minimum required for optimal care and that the transition to lower levels of care are smooth

The dimension scores are linked to a recommended level of care by an algorithm. The six levels of care are briefly outlined in Table II. The focus of these levels is on resource intensity rather than site or specific type of program, which provides flexibly to match the child's needs with the services that are available locally. Each level of care is defined by four service variables: care environment, clinical services, support services, crisis stabilization and prevention services. Some levels of care contain the same resources found at other levels of care, but at a different intensity. With higher levels of care, a greater number and variety of services are used. 


\section{RELIABILITY AND VALIDITY OF THE CASII}

\section{Study Setting}

In order to determine the scale's ability to perform, validity and reliability were tested at four study sites: (1) a community based outpatient program located in an academic training center in Philadelphia, (2) a network of day treatment providers in Portland, Oregon, (3) a consortium of public mental health agencies in the state of North Carolina, and (4) the entire public mental health system in the State of Hawaii. The study was reviewed and approved by the East Tennessee State University Medical School Institutional Review Board. Clinicians were trained and data were collected between September 1999 and June 2000.

\section{Reliability}

\section{Methods}

Seven clinical vignettes were constructed, each oriented to a particular level of care. These vignettes were given to 16 child and adolescent psychiatrists and 78 non-psychiatrists. The 16 child and adolescent psychiatrists had assisted in the construction of the CASII and thus were very familiar with the instrument. Each of these psychiatrists rated the seven vignettes for a total of 105 ratings (the psychiatrist who constructed the vignette did not rate that vignette). The 78 non-psychiatrists with at least bachelor's level education and 6 months clinical experience were trained on the CASII in a 6-hour workshop by one of the two lead authors. Of the non-psychiatrists, $87 \%$ had at least master's level training with an average of over 5 years of post-graduate clinical experience. At the end of their training, these clinicians used the CASII to rate at least two of the seven vignettes chosen at random for a total of 157 ratings. Intraclass correlation coefficients (ICC 2,2) as described by Shrout and Fleiss (1979) were calculated for the child and adolescent psychiatrists and non-psychiatrists separately for each of the dimensions, as well as the composite score.

\section{Results}

As seen in Table III, intra-class correlation coefficients for the subscales for psychiatrists ranged from 0.73 to 0.93 while the composite score was 0.89 . For the non-psychiatrists, the subscale scores ranged from 0.57 to 0.95 while the composite score coefficient was 0.93 . For all of the vignettes, non-psychiatrist rated cases an average of 1.9 points higher than psychiatrists on the total CASII score amounting to less than a full level of care difference on ratings. 
Table III. Intra-Class Correlation Coefficients Comparing Raters on CASII Scores (ICC2,2)

\begin{tabular}{lcc}
\hline Dimension of the CASII & $\begin{array}{c}\text { Child Psychiatrist } \\
\text { Ratings }\end{array}$ & $\begin{array}{c}\text { Non-Psychiatrist } \\
\text { Ratings }\end{array}$ \\
\hline Risk of harm & .87 & .95 \\
Function & .77 & .71 \\
Co-morbidity & .86 & .81 \\
Stress & .78 & .57 \\
Support & .93 & .89 \\
Resilience & .82 & .85 \\
Parent acceptance & .81 & .79 \\
Child acceptance & .73 & .58 \\
Composite score & .89 & .93 \\
\hline
\end{tabular}

\section{Validity}

\section{Methods}

After training on the CASII, the 78 non-psychiatrists completed routine clinical evaluations and then rated these patients with the CASII and either the Child and Adolescent Functional Assessment Scale (CAFAS) as described by Hodges (Hodges \& Wong, 1996) alone or the CAFAS and the Child Global Assessment Scale (CGAS) as described by (Shaffer et al., 1983). CAFAS scores were computed using the 8 CAFAS sub-scales. Patients ages 6 to 18 years old came from inpatient, outpatient, intensive community and residential settings. Modalities for outpatient treatment included individual, family, group psychotherapies, case management, and wraparound services. Pearson correlation coefficients compared the CASII ratings with the CGAS and CAFAS scores.

\section{Results}

CGAS scores in this population of patients $(n=182)$ varied from 23 to 81 with a mean of 40. CASII composite scores varied from 8 to 34 with a mean of 20. Correlation of the CGAS with the subscale scores of the CASII varied between 0.41 to 0 (see Table IV). Those sub-scale correlations related to the child's clinical presentation that would be expected to correlate with CGAS (function, risk of harm and resilience) were 0.41 to 0.26 while those sub-scales having to do with environment and not related to the child directly (environmental support, parent acceptance) were close to 0 . The correlation of CGAS with the CASII Co-morbidity subscale was also close to 0 .

All patients who had CGAS ratings also had CAFAS ratings. In addition, there were 432 patients who had only CAFAS ratings ( $N=614$ for CAFAS/CASII rating combinations). Mean CASII composite score on these 614 patients was 20 with a 
Table IV. Pearson Correlations of CASII Scores with CGAS and Total CAFAS

\begin{tabular}{lcc}
\hline CASII Dimensions & $\begin{array}{c}\text { Correlation with } \\
\text { CGAS scores } \\
(n=182)\end{array}$ & $\begin{array}{c}\text { Correlations with } \\
\text { CAFAS composite } \\
\text { score }(N=614)\end{array}$ \\
\hline Risk of Harm & -.37 & .51 \\
Function & -.41 & .52 \\
Co-Morbidity & -.05 & .41 \\
Stress & -.28 & .35 \\
Support & -.05 & .22 \\
Resilience & -.26 & .50 \\
Parent Acceptance & -.02 & .11 \\
Child Acceptance & -.24 & .31 \\
CASII Total Score & -.33 & .62 \\
\hline
\end{tabular}

range from 8 to 34 while CAFAS composite score mean was 96 with a range from 0 to 200. Table IV also shows the Pearson correlation coefficients between the CASII scores and the CAFAS composite score. As with the CASII-CGAS correlations, those CASII scales that reflect attributes about the child were moderately correlated with the CAFAS composite score: risk of harm (.51), function (.52) and resilience (.50). The CASII co-morbitidy scale was more highly correlated with the CAFAS than the CGAS (.41). Also, just as with the CGAS comparison, the correlation of CAFAS to CASII subscales having to do with environment and not related to the child directly (environmental support, parent acceptance) was lower (.11.22). For comparison, for those patients who had both CAFAS and CGAS scores $(n=182)$, the correlation between them was 0.50 .

\section{DISCUSSION}

The CASII/CALOCUS was designed with consideration for what is known about children in the context of our present system of mental health care. The purpose of the CASII/CALOCUS is to assist clinicians in determining the needed level of care for an individual child and family. On a more global level, the CASII/CALOCUS can assist our society in balancing the equation between individual clinical need on the one side and resource availability on the other side. It is therefore, not surprising that in its short existence, the CASII/CALOCUS has been adopted by managed care organizations to assist in allocating resources to individual clients on the one hand, and by state public health agencies to demonstrate appropriate resource provision (including sites where class action suits demanding appropriate care have resulted in court oversight of resource allocation using the CASII) on the other hand.

In a comprehensive review of level of care determination tools, Lyons and Abraham (2001) evaluated the CASII/CALOCUS favorably, citing its clinical 
utility. Testing of the CASII in this field trial suggests this instrument can be used reliably by a broad range of clinicians with relatively brief training $(6 \mathrm{~h})$, with a much higher level of inter-rater reliability for level of care determination than has been demonstrated previously using other methods (Bickman et al., 1997). In terms of the necessary clinical experience needed by the raters, the subscale scores for the child psychiatrists were more consistent, but the composite score for non-psychiatric clinicians was extremely reliable. Another finding was that psychiatrists tended to rate slightly lower (less severe) than non-psychiatrists. This is ideal since it would be preferable to have less experienced clinicians be more cautious, particularly with regard to safety issues. The difference between these two groups, however, was clinically negligible.

Validity testing indicates that there is moderate correlation between conventionally used scales (CGAS and CAFAS) and the CASII-particularly the composite scores. In this study we trained clinicians in the use of the CASII but not in the use of the CAFAS or the CGAS. Both of these scales were being used routinely at the test sites. Clinicians were not tested on their proficiency with the CAFAS or the CGAS. It is also encouraging to see that those CASII subscales that measure the child attributes correlate more highly with the CAFAS and CGAS scores, while those subscales that measure environment or engagement have much lower correlation, further supporting the validity of the CASII.

It is curious that co-morbidity correlated poorly with the CGAS, but better with the CAFAS. Although it would be expected that CGAS might take comorbidity into account, it appears that it does not. It is also curious that environmental stress is highly correlated with CGAS. Although environmental stress is related to the child's clinical state, these correlations might be expected to be lower than resilience. During the training, it became obvious that less well-trained clinicians have difficulty distinguishing between environmental stresses and disruptions that children themselves create (such as getting expelled from school).

More studies of this instrument are warranted to further establish its evidence base and validity. Studies of prospective validity (against actual level of care placement and its attendant outcome) and inter-rater reliability testing in the field are underway. Studies that address limitations of the current study (such as a larger sample size and more diverse service settings) are also indicated. Finally, the CASII should be evaluated as an outcome evaluation instrument as well as a service needs and utilization research tool. Combined with stratified epidemiological sampling methods, it could be of immeasurable value in local and national systems of care evaluation and planning.

\section{ACKNOWLEDGMENTS}

The field study was supported in part by a Federal grant from the Center for Mental Health Services Branch of Substance Abuse Mental Health Services 
Administration contract \#282-98-0029, sub-task C through the American Institute for Research. All the logistical support for the development of the instrument and national field study came from the unflagging work of Kristin Kroeger-Ptakowski and through the workgroup on Community Based Systems of Care of the American Academy of Child and Adolescent Psychiatry.

\section{REFERENCES}

Alegria, M., Canino, G., Lai, S., Ramirez, R. R., Chavez, L., \& Rusch, D. (2004). Understanding caregivers' help-seeking for Latino children's mental health care use. Medical Care, 42, 447455.

Ambrosini, P., \& Dixon, J. F. (1996). K-SADS-IV-R Manual. Unpublished manuscript.

Anderson, R. L., \& Estle, G. (2001). Predicting level of mental health care among children served in a delivery system in a rural state. Journal of Rural Health, 17, 259-265.

Bickman, L., Karver, M. S., \& Schut, L. J. (1997). Clinician reliability and accuracy in judging appropriate level of care. Journal of Consulting and Clinical Psychology, 65, 515-520.

Book, J., Harbin, H., Marques, C., \& Silverman, C. (1995). The ASAM and Green Spring alcohol and drug detoxification and rehabilitation criteria for utilization review. American Journal on Addictions, 4, 187-197.

Brannan, A. M., Heflinger, C. A., \& Foster, E. M. (2003). The role of caregiver strain and other family variables in determining children's use of mental health services. Journal of Emotional and Behavioral Disorders, 11, 78-92.

Curtiss, F. R. (1985). Analysis of nationwide pharmacy charges per DRG. American Journal of Hospital Pharmacology, 42, 2168-2174.

Deane, F. P., Huzziff, R., \& Beaumont, G. (1995). Discharge planning: levels of care and behavioral functioning in long-term psychiatric inpatients transferred to community placements. Community Mental Health in New Zealand, 9, 18-27.

Endicott, J. (1981). Diagnostic interview schedule: reliability and validity. Archives of General Psychiatry, 38, 1300-1301.

Fallon, T. J., \& Dogin, J. (2005). Public sector dynamics for child mental health. In T. Petti \& C. Salguero (Eds.), Community child and adolescent psychiatry: A manual of clinical practice and consultation (pp. 17-30). Washington, DC: American Psychiatric Press, Inc.

Foster, E. M., Saunders, R. C., \& Summerfelt, W. T. (1996). Predicting level of care in mental health services under a continuum of care. Evaluation and Program Planning, 19, 143-153.

Haley, M. J. (1980). What is a DRG? Top Health Care Finance, 6(4), 55-61.

Hazell, P. L., Tarren-Sweeney, M., Vimpani, G. V., Keatinge, D., \& Callan, K. (2002). Children with disruptive behaviors II: clinical and community service needs. Journal of Pediatric and Child Health, 38, 32-40.

Hodges, K., Doucette-Gates, A., \& Kim, C. S. (2000). Predicting service utilization with the Child and Adolescent Functional Assessment Scale in a sample of youths with serious emotional disturbance served by center for mental health services-funded demonstrations. Journal of Behavioral Health Services Research, 27, 47-59.

Hodges, K., \& Wong, M. (1996). Psychometric characteristics of a multidimensional measure to assess impairment: The Child and Adolescent Functional Assessment Scale. Journal of Child and Family Studies, 5, 445-467.

Lyons, J. S., Mintzer, L. L., \& Kisiel, C. L. (1998). Understanding the mental health needs of children in residential treatment. Professional Psychology: Research and Practice, 29, 582-587.

Lyons, J. S., Griffith, G., Quintenz, S., Jenuwine, M., \& Sasha, M. (2003). Clinical and forensic outcomes from the Illinois Mental Health Juvenile Justice Initiative. Psychiatric Services, 54, 1629-1634.

Lyons, J. S., MacIntyre, J. C., Lee, M. E., Carpinello, S., Zuber, M. P., \& Fazio, M. L. (2004). Psychotropic medications prescribing patterns for children and adolescents in New York's Public Mental Health System. Community Mental Health Journal, 40, 101-118. 
McKay, J. R., Cacciola, J. S., McLellan, T., Alterman, A. I., \& Wirtz, P. W. (1997). An initial evaluation of the psychosocial dimensions of the American Society of Addiction Medicine criteria for inpatient versus intensive outpatient substance abuse rehabilitation. Journal of Studies on Alcohol, $58,239-252$.

Newman, F. L., Griffin, B. P., Black, R. W., \& Page, S. E. (1989). Linking level of care to level of need: Assessing the need for mental health care for nursing home residents. American Psychologist, 44 , $1315-1324$.

Pumariega, A. J., \& Cross, T. L. (1997). Cultural competence in child psychiatry. In J. Noshpitz \& N. Alessi (Eds.), Basic handbook of child and adolescent psychiatry (Vol. IV, pp. 473-484). New York: John Wiley \& Sons.

Shaffer, D., Gould, M. S., Brasic, J., Ambrosini, P., Fisher, P., Bird, H., et al. (1983). A Children's Global Assessment Scale (CGAS). Archives of General Psychiatry, 40, 1228-1231.

Shaffer, D., Schwab-Stone, M., Fisher, P., Cohen, P., Piacentini, J., Davies, M., et al. (1993). The Diagnostic Interview Schedule for Children-Revised Version (DISC- R): I. Preparation, field testing, inter rater reliability, and acceptability. Journal of the American Academy of Child and Adolescent Psychiatry, 32, 643-650.

Shrout, P. E., \& Fleiss, J. L. (1979). Intra-class correlations: Uses in assessing rater reliability. Psychological Bulletin, 86, 420-428.

Sowers, W., George, C., \& Thompson, K. (1999). Level of Care Utilization System for Psychiatric and Addiction Services (LOCUS): A preliminary assessment of reliability and validity. Community Mental Health Journal, 35, 545-563.

Srebnik, D., Uehara, E., \& Smukler, M. (1998). Field test of a tool for level-of-care decisions in community mental health systems. Psychiatric Services, 49, 91-97.

Stroul, B., \& Friedman, R. (1996). A system of care for children and youth with severe emotional disturbances. Washington, DC: Georgetown University Child Development Center, CASSP Technical Assistance Center.

Teagle, S. E. (2002). Parental problem recognition and child mental health service use. Mental Health Services Research, 4, 257-266.

Uehara, E. S., Smukler, M., \& Newman, F. L. (1994). Linking resource use to consumer level of need: Field test of the Level of Need-care Assessment (LONCA) method. Journal of Consulting and Clinical Psychology, 62, 695-709.

VanDenBerg, J., \& Grealish, M. (1996). Individualized services and supports through the wraparound process: Philosophy and procedures. Journal of Child and Family Studies, 5, 7-21.

Van der Linden, J., Drukker, M., Gunther, N., Feron, F., \& Van Os, J. (2003). Children's mental health service use, neighborhood socioeconomic deprivation, and social capital. Social Psychiatry and Psychiatric Epidemiology, 38, 507-514.

Welner, Z., Reich, W., Herjanic, B., Jung, K.G., \& Amado, H. (1987). Reliability, validity, and parentchild agreement studies of the Diagnostic Interview for Children and Adolescents (DICA). Journal of the American Academy of Child and Adolescent Psychiatry, 26, 649-653. 